the drawn expression of the face, the sunken, sleepless eyes, the semi-flexed attitude on standing or walking, and the care with which she carried herself (particularly in going down a step). These, and especially the constant abdominal pain, the importance of which was gauged by its power of preventing sleep, were invaluable in guiding those who were responsible for the case to right action, whereby the disease was removed and the patient restored to health. A woman's account of pain is proverbially unreliable. The test or measurement of this by its power of preventing sleep is a practical suggestion which I can thoroughly recommend. When necessary, confirmation or otherwise of the patient's statement on this point can be usually obtained from someone else living in the same house. When abdominal pain is bad enough to keep a patient awake all night it should never be treated lightly or disregarded. On the other hand, too, it should never be hastily or rudely stopped by opiates. It is a sign of great value. If it is the only sign we have its importance may be supreme. How to relieve it wisely is a question which may call for the most careful consideration, and in that consideration the question of operative treatment should usually have an important place.

Birmingham.

\section{CAN ATROPHY OF THE ENLARGED PRO- STATE BE INDUCED BY PARTIAL REMOVAL?}

By C. MaNsell MOULLiN, M.D. Oxon., F.R.C.S. ENG, SURGEON TO THE LONDON HOSPITAL.

IT has often been stated that operations upon the enlarged prostate not involving complete removal, or even removal of any large amount, are followed by permanent reduction in the size of the gland, altogether out of proportion to the immediate effect-in other words, that after partial operations the prostate may undergo a kind of involution or atrophy. If this can be established as a fact, the conclusion is a very important one. The question us to the amount of the enlargement that should be removed in performing sunra-pubic prostatectomy is by no means settled. In the Hunterian Lectures on the operative treatment of the enlarged prostate I stated, as the conclusion at which $I$ bad arrived, that if the operation is to prove successful the whole of the vesical mass must be removed, whether it springs from the lateral lobes, or is an upgrowth from the posterior wall, or is a detached nodule; and that then the expioration must be extended down the whole length of the prostatic urethra. This, Professor White of Philadelphia in the most recently published summary of the surgery of the enlarged prostate will not admit. He says "it may be true, but it has certainly not yet been demonstrated." On the other hand, Mr. Gilbert Barling ${ }^{2}$ reports a remarkable case of supra-pubic prostatectomy in order "to emphasise the necessity for a free removal of prostatic tissue when prostatectomy is undertaken. The want of boldness in doing this is probably the cause of failure in most of the cases where operation has failed to give relief and the bladder muscle is not in a condition of atony." Probably much depends on the kind of growth ; but there is evidently considerable difference of opinion. Cases in which diminution in size has followed operation have been published by many observers. Mr. R. Harrison ${ }^{3}$ describes one in which, after the bladder had been drained through the perineum and prostate for six weeks, all the functional symptoms of enlargement disappeared. The size was reduced so much that little that was abnormal conld be felt through the rectum, and the patient lived for seven years without experiencing further trouble. He also mentions that in several instances in which the bladder had been tapped through the perineum, and the cannula retained, he had noted distinct shrinking in size of the gland, and he states that he feels tolerably sure that a similar effect may follow simple drainage.

Two instances of a similar character have occurred under my own care. In one patient, who died some days after the

1 Annals of Surgery, 1898

2 THE LANCET, June 10th, 1893.

3 Lectures on Surgical Disorders of Urinary Organs, fourth edition, and Brit. Med. Jour., June, 1838. bladder had been tapped through the perineum and prostate, the original direction of the trocar could be easily traced. The part of the track that lay in the median lobe formed a distinct angle with the rest, showing that the relative position occupied by the obstruction before puncture was very different from that it occupied after death. In the other, under the care of $\mathrm{D} c$. Challis of Walthamstow, the same thing was shown in another way. The patient had been tapped in the same fashion for drainage, the prostatic urethra being opened en ronte. A soft rubber tube was inserted. After a few days this was accidentally withdrawn by the patient. On attempting to introduce a rigid guide through the opening as a preliminary to another tube it passed along the urethra instead of across it. The projecting median lobe, which had been of enormous size had shrunk so much that the prostatic urethra had almost regained its normal direction. The diminution on rectal examination was even more striking. Broome of St. Louis, who describes himself as almost alone in America in deprecating the operation of prostatectomy and characterises the proceeding as unjustifiable, describes how, after the wearing of a supra-pubic drainage-tube, the hypertrophied glandular tissue undergoes atrophic changes and a low-level channel is established by physiological regression. "The patients had only to wear the tube during a few months; the longest period was seven (and that patient during this time gained forty-eight pounds in weight), and it now affords me great pleasure and satisfaction to be able to state that they are all well and apparently perfectly and permanently cured." Wishard ${ }^{5}$ in four cases found marked diminution in the size of the rectal tumour after puncturing the lateral lobes with a small galvano-cautery point through the perineum. The punctures were from one-half to threequarters of an inch in depth (in the prostatic tissue, which was exposed through a perineal incision by means of a Fergusson's speculum) and from two to six in number. Packard of Philadelphia wrote to me that after supra-pubic cystotomy for retention following enlargement of the prostate the gland in several of his cases shrunk very decidedly. Two cases in which this occurred are detailed in his paper on Supra-pubic Cystotomy in the Transactions of the American Medical Association for 1887. Professor White describes another case. The patient was sixty-six years of age and had passed no urine voluntarily for more than three vears. There was intense cystitis with albumen and casts ; and "pipe-stem" radial arteries. Small portions of the prostate immediately around and beneath the vesical orifice were removed, and nothing more. The orifice was freed, but no attention was paid to the lateral lobes. "The improvement is so disproportionate to the extent of any interference with the growth that I am convinced it is partly due to subsequent contraction of the remaining portion of the gland." The same thing has been noted after lateral lithotomy. The condition of the bladder has improved more than could be accounted for by the removal of the calculus, and in a few the diminution in the size of the gland has been confirmed by rectal examination. It must be allowed, therefore, that reduction in size does take place in some instances, and that it may follow incision, puncture with a trocar or the galvano-cautery, drainage either by means of the catheter in the urethra or through a supra-pubic opening, or partial excision through the bladder. The question is whether it is due to atrophy induced by the operation, or merely to subsidence of congestion, cicatrisation, and fibroid degeneration of the adenomatous growth. The evidence is wholly clinical. So far as I can ascertain, no one has had the opportunity of examining these glands micro. scopically - the only way in which atrophy could be proved. The first point to note is that nearly every case was operated upon for retention of urine, or for septic cystitis, or for both. Under these conditions, not only is the size of the prostate enormously increased by congestion, but it is made to appear very much larger than it really is. It is surrounded by the distended and of ten thrombosed prostatic plexus of veins, and the mass these form is as hard as the prostate itself. The finger can distinguish through the wall of the rectum nothing but uniform enlargement, and at the time of the retention it.is impossible to say how much of this enlargement is due to prostatic overgrowth and how much to simple congestion. Time alone can tell. The prostate in ordinary cases of retention treated by catheterisation and rest in bed often diminishes very greatly in size in the course of a few weeks, and so.

4 Transactions of the Missouri State Medical Association, 1893. 5. Journal of Cutaneous and Genito-Urinary Diseases, 1892. 
far as my own two cases are concerned I do not think that the reduction in either of them, great as it was, was more than could reasonably be accounted for in this way. In most, however, there was another, and perhaps a more important, factor in bringing about this result. It has been shown by Griffiths, ${ }^{6}$ and it has been confirmed by my own investigations and those of others, that, while the primary hange in enlargement of the prostate is a form of glandular overgrowth, fibroid degeneration, secondary to this, always follows at a very early period in some cases, leading to an exceedingly dense mass of scirrhous hardness, and much later in others ; and I think it is allowable to infer that this fibroid transformation, if it has not already commenced, might be started from foci of cicatricial contraction following suppuration. Certainly the method employed in nearly all these cases was such as would cause suppuration and tolerably extensive cicatrisation afterwards. The maintenance of a cannula, for example, for many weeks together in the middle of an enlarged gland, or puncture with a galvano"cautery or the removal of portions of the mass through a supra-pubic opening in a bladder affected with intense cystitis, would undoubtedly lead to this. It is to this, I believe, that the benefit that has undoubtedly been experienced in many of these cases is due; and this, too, affords a reasonable explanation of the fact that the result in (unfortunately) the greater number has been negative-the fibroid transformation was already so far advanced in them that further contraction could not take place.

There is no evidence, so far as I have been able to ascertain, that atrophy has ever been induced in this way. True atrophy does occur after castration. The gland shrinks to a small fibrous nodule. But it is not said in any case that I have discovered that the prostate contracted to less than its normal size. All that is said is that the gland diminished to sach an extent that nothing that was abnormal could be feit per rectum, or that in some the obstruction to micturition, in others the obstacle that prevented the passage of a catheter, almost disappeared ; and this is not sufficient.

There are certain corollaries of some importance that follow from this.

1. Prostatectomy should not be performed shortly after an attack of acute retention. It is not possible, without waiting a little, to say how much of the enlargement is due to congestion, and the hæmorrhage may be severe.

2. In cases of septic cystitis it may be advisable to perform the operation in two stages. First the bladder should be arained by supra-pubic cystotomy, then after a few days, when the congestion has subsided and the urine has lost its foul and septic character, the obstruction at the neck should be dealt with. It is conceivable from the amount of shrinkage that has taken place that in some cases the second part of the operation may not be required, and there would be at least this advantage that the wound left after the growth had been excised-always a very ragged onewould not be bathed in putrid urine.

3. If prostatectomy, with the view of establishing a lowlevel urethra, is thought advisable after the congestion has subsided, the operation, as I mentioned in my lectures, should be thorough. Every atom of the obstruction then must be due to the growth. This is especially necessary where, as in Mr. Gilbert Barling's case, the prostate is very hard. If the overgrowth has alrcady passed into the stage of fibroid induration, it cannot contract any more. It does not follow, however, that if the prostate is soft and adenomatous the portion removed should be a small one, in the hope that condensation and contraction would do the rest.

4. The merits of prostatotomy are not due to the division of the gro wth, but to the changes induced by subsequent drainage.

Wimpole-street, $\mathrm{W}$.

\section{A CASE OF CIRRHOSIS OF THE LIVER PRESENTING SOME UNUSUAL SYMPTOMS.}

BY H. W. WEBBER, M.D. \& B.S. LOND.

A PUBLIC-HOUSE-KEEPER aged fifty-one was seen first on Fov. 11th, 1893, complaining of abdominal pain and dissomfort, with flatulence, nausea and a little sickness, and pain in the lower parts of the back. There had been con-

6 Journal of Anatomy and Physiology, 1888, 1889, 1890. stipation for two days; no headache was complained of. The tongue was coated, the pulse 90 , and the temperature $100.8^{\circ} \mathrm{F}$. The patient had been a beavy drinker in former years, and had continued this habit, but with more moderation, latterly. He was ordered an effervescing mixture and low diet. On the 12th the bowels acted slightly and the temperature was $101^{\circ}$. On examination of the abdomen the liver dulness was found to commence above at the lower border of the fifth rib, while below the edge of the liver could be indistinctly felt at a distance of rather more than an inch from the costal margin; no tenderness of the liver was felt on deep pressure. The abdominal walls were fatty, and scattered over the skin of the abdomen and lower part of the chest a few dilated bloodvessels were present. The edge of the spleen was not palpalole or the splenic dulness increased; no peritoneal exudation was present. On examination numerous dilated vessels and petechial papules were found in the skin over the face, arms, and back. On the 15th the temperature was $100^{\circ}$, and pain in the back was still complained of, but the nausea had ceased. The bowels now acted once or twice a day ; the urine was high-coloured and contained lithates, but no albumen. On the 19th the patient suffered slightly from epistaxis. The respiration was somewhat laboured and wheezy, though no adrentitious sounds were, heard on auscultation, nor was there any expectoration. He was now ordered a mixture containing potassium citrate, salicylate of soda, and ammonium acetate every four hours, and was put on slop diet. On the 23rd the temperature, which had been $100^{\circ}$ for two days, rose to $103^{\circ}$, the patient's face was flushed and the eyes injected, the tongue was coated, and the pulse 120 . The oozing from the nares still continued. The motions were of the colour and consistence of putty; the urine was high coloured, depositing lithates. The edge of the liver was palpable, more distinctly than at first, two inches below the costal margin, but only slightly tender on deep pressure. He was ordered quinine sulphate (one grain) in pill form every four hours, with the previous mixture. On the 24 th the temperature fell to $100^{\circ}$, only to rise the day after to $102^{\circ}$. On the 26th it had fallen to $99^{\circ}$, but on the 27 th it was $103^{\circ}$. On the latter day the patient had profuse epistaxis, and complained of headache. The bowels continued to act rather irregularly, but generally at least one motion was passed every day; it was of the same character as noted previously. No reaction for bile could be obtained from the urine, though the tests for this were applied on several occasions. The patient was now treated with a mixture containing chlorate of potash and Warburg's tincture given every four hours, with a dose of castor-oil when required to assist the action of the bowels. During the early part of December the condition very gradually improved, and the temperature kept generally at a much lower level. There was epistaxis at times, though not profuse. In the third week of December he was able to be about a little. This improvement, however, only lasted for a few days, and on Dec. 25 th he had to take to his bed again. His condition at this time was as follows : the face was fiushed and the conjunctival vessels somewhat dilated there was no jaundice. The skin over the body generally was of a pale lemon or primrose tint, with numerous scattered papular petechial spots. Blood oozed occasion. ally from the nose. The tongue was coated on the dorsum and red at the edges. The whole of the fauces and pharynx were intensely red and covered with yellowish stringy mucus. The patient was tronbled at times with fits of coughing, when be would expectorate a little frothy blood; he was constantly hoarse. No abnormal physical signs were discovered in the chest. The edge of the liver could be felt at a distance of three inches from the costal margin, rounded, the viscus now being distinctly tender. There was no enlargement of the spleen nor any signs of fluid in the peritoneal cavity. The cardiac sounds presented nothing abnormal ; the pulse was generally 120 , full, soft, and of medium tension, the temperature varying from $99^{\circ}$ to $1002^{\circ}$ in the morning and from $101^{\circ}$ to $102.4^{\circ}$ in the evening. The throat was painted with borax and glycerine and an opiate linctus given to relieve the cough. On Dec. 30th a small percentage of albumen was found in the urine. On the 31st the patient had an attack of bleeding from the left nostril, which was so profuse that it was plugged with strips of lint soaked in hazeline. On the evening of Jan. 1st, 1894, there was a discharge of blood-stained fluid from the left ear. On the 2nd profuse hæmorrhage, requiring plugging, took place from the right nostril, and on the 3rd there was a blood-stained discharge from the right ear. No albumen was found in the 